\title{
Analysis and cloning of the synthetic pathway of the phytohormone indole-3-acetic acid in the plant-beneficial Bacillus amyloliquefaciens SQR9
}

\author{
Jiahui Shao ${ }^{1,2+}$, Shuqing $\mathrm{Li}^{2+}{ }^{\text {, Nan }}$ Zhang $^{2}$, Xiaoshuang Cui ${ }^{2}$, Xuan Zhou ${ }^{2}$, Guishan Zhang ${ }^{1}$, Qirong Shen ${ }^{2}$ \\ and Ruifu Zhang ${ }^{1,2^{*}}$
}

\begin{abstract}
Background: The plant growth-promoting rhizobacteria (PGPR) strain Bacillus amyloliquefaciens SQR9, isolated from the cucumber rhizosphere, protects the host plant from pathogen invasion and promotes plant growth through efficient root colonization. The phytohormone indole-3-acetic acid (IAA) has been suggested to contribute to the plant-growth-promoting effect of Bacillus strains. The possible IAA synthetic pathways in B. amyloliquefaciens SQR9 were investigated in this study, using a combination of chemical and genetic analysis.

Results: Gene candidates involved in tryptophan-dependent IAA synthesis were identified through tryptophan response transcriptional analysis, and inactivation of genes ysnE, dhaS, ycIC, and yhcX in SQR9 led to 86, 77, 55, and $24 \%$ reductions of the IAA production, respectively. The genes patB (encoding a conserved hypothetical protein predicted to be an aminotransferase), yclC (encoding a UbiD family decarboxylase), and dhaS (encoding indole 3-acetaldehyde dehydrogenase), which were proposed to constitute the indole-3-pyruvic acid (IPyA) pathway for IAA biosynthesis, were separately expressed in SQR9 or co-expressed as an entire IAA synthesis pathway cluster in SQR9 and $B$. subtilis 168, all these recombinants showed increased IAA production. These results suggested that gene products of $d h a S, p a t B, y c|B, y c| C, y h c X$ and $y s n E$ were involved in IAA biosynthesis. Genes patB, yclC and dhaS constitute a potential complete IPyA pathway of IAA biosynthesis in SQR9.
\end{abstract}

Conclusions: In conclusion, biosynthesis of IAA in B. amyloliquefaciens SQR9 occurs through multiple pathways. Keywords: Bacillus, Biosynthesis, Biotechnology, Phytohormone, Gene transcription, IAA biosynthesis pathway

\section{Background}

Promotion of plant growth by Bacillus strains inhabiting the rhizosphere is well documented [1-4]. The plant growth-promoting effect of rhizospheric bacilli results from the synergy of several factors, including the production of phytohormones such as indole-3-acid (IAA),

\footnotetext{
*Correspondence: zhangruifu@caas.cn

†Jiahui Shao and Shuqing Li contributed equally to this paper

1 Key Laboratory of Microbial Resources Collection and Preservation,

Ministry of Agriculture, Institute of Agricultural Resources and Regional

Planning, Chinese Academy of Agricultural Sciences, Beijing 100081,

People's Republic of China

Full list of author information is available at the end of the article
}

the secretion of extracellular phytase under conditions of phosphate limitation and in the presence of phytate [5, $6]$, and the emission of volatile compounds $[2,7,8]$.

It appears that the secreted IAA plays an important role in the plant-growth-promoting effect of some plantbeneficial bacteria [9-11]. IAA is a common phytohormone with the capacity to regulate nearly every aspect of plant growth and development, such as cell division, elongation, fruit development and senescence [12-15]. IAA produced by plant-growth-promoting bacteria also acts in the rhizosphere, including stimulation of roothair formation by increasing the number and length of lateral and primary roots when it is within a certain 
concentration range [16-18]. IAA synthesis in bacteria may lead to increased rooting, as observed in studies with Azospirillum mutants with altered IAA production [19]. This increased rooting enhanced plants' water and nutrient uptake and root exudation, which in turn stimulated bacterial root colonization. A study by Ahmed and Hasnain [20] demonstrated that inoculation of two IAAproducing Bacillus strains could significantly increase the shoot length, root length and number of leaves on the plant compared to non-inoculated treatments, suggesting the possible use of IAA-producing bacteria as effective plant-growth-promoting inoculants.

The ability to synthesize IAA is a common trait in rhizospheric bacteria, and tryptophan has been identified as a main precursor for IAA biosynthesis pathways $[21,22]$. To date, studies on the key genes or proteins involved in IAA production are few and have mostly been focused on a single specific gene or protein in a biosynthetic pathway. In plants, four tryptophan-dependent IAA synthesis pathways have been proposed, the indole3-pyruvic acid (IPyA), indole-3-acetamide (IAM), indole3 -acetonitrile (IAN), and tryptamine (TAM) pathways, and they have also been postulated in bacteria [23, 24]. The IPyA pathway is thought to exist in both plants and bacteria, including phytopathogenic and beneficial bacteria [23]. The gene encoding the key enzyme indole3-pyruvate decarboxylase (IPDC), a decarboxylase that converts IPyA into indole-3-acetylaldehyde, has been identified and characterized in Az. brasilense, Enterobacter cloacae, and Pseudomonas putida [18, 25-27]. In these organisms, inactivation of this pathway resulted in lower IAA production, up to $90 \%$ reduction in $\mathrm{Az}$. brasilense [28], indicating the importance of the IPyA pathway in auxin production. However, the bacterial gene responsible for the aldehyde oxidation step of the IPyA pathway remains elusive. The presence of the IPyA pathway in some phytopathogens was proposed based on the identification of the corresponding intermediates [29, 30]. The IAM pathway is the best-characterized pathway in bacteria [31-33]. This two-step pathway is catalyzed by the enzymes tryptophan-2-monooxygenase (IaaM) and IAM hydrolase (IaaH), encoded by the iaaM and iaaH genes, respectively $[23,24]$. The TAM pathway has been suggested in B. cereus and Azospirillum by the identification of tryptophan decarboxylase activity [34] and the conversion of exogenous tryptophan to IAA [35], but the genes involved in this pathway still need to be confirmed in bacteria. The biosynthesis of IAA via IAN has been extensively studied in plants, but it has not been characterized in bacteria. The steps leading to the conversation of tryptophan to IAN are still a matter of debate, but the last step of this pathway, converting IAN into IAA, was catalyzed by a nitrilase [36]. The possible IAN pathway in bacteria such as Alcaligenes faecalis was suggested due to the detection of nitrilase with specificity for indole3 -acetonitrile $[37,38]$. Further, the nitrilase in P. syringae $\mathrm{B} 728 \mathrm{a}$ is capable of hydrolyzing indole-3-acetonitrile to IAA, allowing this strain to use indole-3-acetonitrile as the nitrogen source [39]. Tryptophan-independent pathway was also suggested although no enzyme involved in this pathway has been characterized. In Arabidopsis thaliana, tryptophan-independent pathway was suggested based on the observation that tryptophan synthesis mutants increased IAA conjugates [40, 41]. In $A z$. brasilense, feeding experiments with labeled substrates revealed that $90 \%$ of the IAA is synthesized via the tryptophan-independent pathway when tryptophan was absent in the medium [28].

Though much work has been performed on the IAA synthesis pathway in both plants and bacteria, as described above, the details of the biosynthetic pathways utilized by Gram-positive bacteria remain less clear. Stimulation of IAA production by tryptophan was previously described for Gram-positive bacteria [9]. In the phytopathogenic Rhodococcus fascians, the main biosynthetic route for IAA is the IPyA pathway, and the ipdC gene was functionally identified and expressed in Paenibacillus polymyxa E681 [42, 43]. In B. amyloliquefaciens FZB42, a fivefold increase in IAA secretion was recorded in the presence of tryptophan [9]. Deletion of the gene $y s n E$, which encodes a putative tryptophan acetyltransferase, results in a $72 \%$ decrease of IAA production in FZB42 [9]. Meanwhile, an FZB42 mutant with a deletion of the putative nitrilase gene $y h c X$ only produced $50 \%$ of the wild type level of IAA [9]. These results indicated that the IAA synthesis in B. amyloliquefaciens FZB42 was tryptophan-dependent and that the IAN pathway and another uncharacterized pathway involving tryptophan acetyltransferase were the main routes for IAA biosynthesis [9].

The PGPR strain B. amyloliquefaciens SQR9 was isolated from cucumber rhizosphere (Table 1), and it showed efficient suppression of soil-borne $F$. oxysporum and protected the host from pathogen invasion [44-46]. Our previous study indicated that $B$. amyloliquefaciens SQR9 is an outstanding root colonizer with a population of $10^{6} \mathrm{CFU} \mathrm{g}^{-1}$ root in rhizoplane after 23 days of inoculation [44], which was a potential factor contributing to its ability to promote plant growth. A major antifungal antibiotic, bacillomycin $\mathrm{D}$, and the global regulator $\mathrm{AbrB}$ were reported to be involved in the root colonization of B. amyloliquefaciens SQR9 [47, 48]. B. amyloliquefaciens SQR9 was shown to produce IAA, and this was suggested to contribute to its plant-growth-promoting effect [49]. Furthermore, addition of L-tryptophan in its growth medium significantly increased the yield of IAA [49]. 
Table 1 Strains and plasmids used in this study

\begin{tabular}{|c|c|c|}
\hline Strains or plasmids & Description & Reference or source \\
\hline \multicolumn{3}{|l|}{ Escherichia coli } \\
\hline E. coli top10 & $\begin{array}{l}\text { F-mcrA } \Delta \text { (mrr-hsdRMS-mcrBC) } \Psi 80 \text { lacZ } \Delta \text { M15 } \Delta \text { lacX74 nupG recA1 } \\
\text { araD139 } \Delta \text { (ara-leu) } 7697 \text { galE15 galK } 16 \text { rpsL (StrR) end } A 1 \lambda-\end{array}$ & Invitrogen (Shanghai) \\
\hline \multicolumn{3}{|l|}{ B. amyloliquefaciens } \\
\hline SQR9 & Wild-type isolate & {$[44]$} \\
\hline$\Delta$ dhas & $\Delta d h a s:: \mathrm{Cm}^{r}$ & This study \\
\hline$\Delta$ patB & $\Delta p a t B:: \mathrm{Cm}^{r}$ & This study \\
\hline$\Delta y c \mid B$ & $\Delta y c \mid B:: \mathrm{Cm}^{r}$ & This study \\
\hline$\Delta y c l C$ & $\Delta y c / C:: \mathrm{Cm}^{r}$ & This study \\
\hline$\Delta y h c X$ & $\Delta y h c X:: \mathrm{Cm}^{r}$ & This study \\
\hline$\Delta y s n E$ & $\Delta y s n E:: \mathrm{Cm}^{r}$ & This study \\
\hline patB-E & B. amyloliquefaciens SQR9 with pUBC19-P43-patB (kan'r) & This study \\
\hline yclC-E & B. amyloliquefaciens SQR9 with pUBC19-P43-yclC (kan') & This study \\
\hline dhaS-E & B. amyloliquefaciens SQR9 with pUBC19-P43-dhaS (kan') & This study \\
\hline SQR9-E & B. amyloliquefaciens SQR9 with pUBC19-P43-BCS (kan r) & This study \\
\hline SQR9-CK & B. amyloliquefaciens SQR9 with pUBC19-P43 (kan') & This study \\
\hline \multicolumn{3}{|l|}{ B. subtilis } \\
\hline 168 & Wild-type isolate & Lab strain \\
\hline $168-\mathrm{E}$ & B. subtilis 168 with pUBC19-P43-BCS (kan') & This study \\
\hline $168-C K$ & B. subtilis 168 with pUBC19-P43 (kan') & This study \\
\hline \multicolumn{3}{|l|}{ Plasmids } \\
\hline pUBC19 & Ampr $\mathrm{Km}^{\mathrm{r}}$; B.subtilis-E. coli shuttle vector & {$[47]$} \\
\hline pNW33n & $\mathrm{Cm}^{r}$ & {$[46]$} \\
\hline pUBC19-P43 & pUBC19 containing P43 promoter & This study \\
\hline pUBC19-P43-patB & pUBC19 containing P43 promoter and patB & This study \\
\hline pUBC19-P43-yclC & pUBC19 containing P43 promoter and yclC & This study \\
\hline pUBC19-P43-dhas & pUBC19 containing P43 promoter and dhas & This study \\
\hline pUBC19-P43-E & pUBC19 containing P43 promoter and fusion fragments for expression & This study \\
\hline pUBC19-dhaS & pUBC 19 containing dhas & This study \\
\hline pUBC19-yclC & pUBC 19 containing yclC & This study \\
\hline pUBC19-ysnE & pUBC 19 containing ysnE & This study \\
\hline
\end{tabular}

$\mathrm{Cm}^{r}$ chloroamphenicol resistant, $\mathrm{kan}^{r}$ kanamycin resistant, $A m p^{r}$ Ampicillin resistant

Through genomic searching, the candidate genes potentially involved in the IAA biosynthesis pathways were obtained, and transcriptional responses to L-tryptophan and gene mutation analysis identified the key genes for IAA biosynthesis in SQR9. Moreover, a possible complete IPyA pathway was cloned and successfully expressed in both B. amyloliquefaciens SQR9 and B. subtilis 168.

\section{Results}

Screening of genes likely to be involved in IAA biosynthesis in the B. amyloliquefaciens SQR9 genome

Based on the proposed IAA biosynthesis pathways in plants and bacteria [23, 24], the entire B. amyloliquefaciens SQR9 genome was mined for genes involved in each step of IAA biosynthesis. The gene candidates were screened according to their deduced protein domains, which show putative enzyme activities already known in IAA metabolism (Table 2). In the IPyA pathway, genes encoding putative amino transferases including pat $B$, bio $A$ and $y o t D$; the decarboxylase genes $(y d a P, p y c A$, padC, $y c l B$, and $y c l C$ ) may be involved in the indolepyruvate decarboxylation reaction in the IPyA pathway and the tryptophan decarboxylation reaction in the TAM pathway. In both the IPyA and TAM pathways, the final step is the conversion of indole-3-acetaldehyde into IAA, which is catalyzed by indole-3-acetaldehyde dehydrogenase; in SQR9, the genes aldX, dhaS, yfmT, and $y w d H$ may encode this enzyme. However, the genes coding for the putative amine oxidase in the first step of the TAM pathway were not detected in the SQR9 genome. For the possible IAN pathway, only the nitrilase gene $(y h c X)$ was identified; the tryptophan acetyltransferase gene $y s n E$, 
Table 2 Possible B. amyloliquefaciens SQR9 genes involved in tryptophan dependent IAA production

\begin{tabular}{|c|c|c|}
\hline IAA synthesis pathways & Enzymes proposed in each step & Putative genes in SQR9 and accession numbers ${ }^{a}$ \\
\hline \multirow[t]{3}{*}{ IPyA } & Amino transferase & patB (V529_31110), bioA(V529_17980), yotD(V529_21800) \\
\hline & Indolepyruvate decarboxylase & $\begin{array}{l}\text { ydaP(V529_04190), pycA (V529_14260), padC(V529_34370), yclB(V529_03390), } \\
\text { ycIC(V529_03400) }\end{array}$ \\
\hline & IAAld dehydrogenase & aldX(V529_39560), dhaS(V529_19360),yfmT(V529_06950), ywdH(V529_29500) \\
\hline \multirow[t]{2}{*}{ IAM } & Trp mono-oxygenase & Not detected \\
\hline & IAM hydrolase & Not detected \\
\hline \multirow[t]{3}{*}{ TAM } & Trp decarboxylase & $\begin{array}{l}\text { ydaP(V529_04190), pycA(V529_14260), padC(V529_34370), yclB(V529_03390), } \\
\text { yclC(V529_03400) }\end{array}$ \\
\hline & Amine oxidase & Not detected \\
\hline & IAAld dehydrogenase & aldX(V529_39560), dhaS(V529_19360),yfmT(V529_06950), ywdH(V529_29500) \\
\hline IAN & Nitrilase & yhcX(V529_08860) \\
\hline Other pathway & Tryptophan acetyltransferase & ysnE(V529_38080) \\
\hline
\end{tabular}

a Accession number was shown in bracket. IPyA , IAM, IAN and TAM are abbreviates of indole-3-pyruvic acid, indole-3-acetamide, indole-3-acetonitrile, and tryptamine pathways, respectively

which was involved in the uncharacterized tryptophandependent IAA biosynthesis pathway and was a main route in B. amyloliquefaciens FZB42 IAA biosynthesis [9], was also found in the SQR9 genome. The well-documented indolepyruvate decarboxylase ipdC gene in the IPyA pathway and the tryptophan monooxygenase $(i a a M)$ and indole-3-acetamide hydrolase $(i a a H)$ genes of the well characterized IAM pathway were not detected in the SQR9 genome [24].

Transcriptional responses to tryptophan identified the genes involved in tryptophan-dependent IAA biosynthesis of B. amyloliquefaciens SQR9

Because all the gene candidates were potentially involved in the tryptophan-dependent IAA biosynthesis, the active genes were identified via the transcriptional responses of the screened genes upon the addition of tryptophan. When $3 \mathrm{mM}$ tryptophan was added to the medium, SQR9 IAA production was increased 3.6-fold, indicating that IAA biosynthesis in SQR9 was tryptophan-dependent [49]. Six of the genes were found to be significantly induced by tryptophan (Fig. 1a): patB, encoding a conserved hypothetical protein predicted to be an aminotransferase, increased 3.5 -fold; $y h c X$, a predicted nitrilase encoding gene, increased 3-fold; dhaS, encoding indole 3-acetaldehyde dehydrogenase, increased 2.5-fold; $y s n E$, a predicted tryptophan acetyltransferase encoding gene, increased twofold; $y c l B$, encoding an aromatic-acid decarboxylase, increased 1.5 -fold; and $y c l C$, located in the same operon as $y c l B$, encoding a UbiD family decarboxylase, increased twofold. These six genes were proposed to be involved in the tryptophan-dependent IPyA, TAM, and IAN pathways, as well as an uncharacterized IAA biosynthesis pathway, indicating that multiple IAA biosynthesis pathways existed in B. amyloliquefaciens SQR9. The other eight candidate genes, which were not induced by tryptophan (Additional file 1: Figure S1), were presumably not be involved in the tryptophan-dependent IAA biosynthesis in B. amyloliquefaciens SQR9.

\section{Gene knockout mutants revealed the key genes and pathways contributing to IAA biosynthesis of $B$. amyloliquefaciens SQR9}

To confirm their contribution to IAA production in $B$. amyloliquefaciens SQR9, these six genes were individually deleted, and the IAA productions of these mutants were measured and compared with the wild-type SQR9 (Fig. 1b). All mutant strains showed growth curves comparable to that of wild-type SQR9. Indole-3-acetic acid was defined in SQR9 supernants by monitoring the transition of the parent molecular ion $\mathrm{m} / \mathrm{z} 176$ to the principle daughter ion m/z 130 in LC/MS analysis. Quantification of the IAA amounts present in culture filtrates of gene knockout mutants showed that strains $\triangle \mathrm{ysnE}$, $\Delta \mathrm{dhaS}, \Delta \mathrm{yclC}$, and $\Delta \mathrm{yhcX}$ produced only $14,23,45$, and $76 \%$ of the wild type SQR9 IAA production level, respectively (Fig. 1b), whereas strains $\Delta$ patB and $\Delta y c l B$ produced IAA at levels similar to wild-type SQR9. Complementation of the four mutants with the B. amyloliquefaciens- Escherichia coli shuttle vector pUBC19 carrying the corresponding deleted genes restored the IAA production (Fig. 1b). These results suggested that the pathway including tryptophan acetyltransferase was an important route for IAA biosynthesis in SQR9. The IPyA and TAM pathways also contributed substantially, but the IAN pathway only slightly contributed to IAA production in SQR9. 


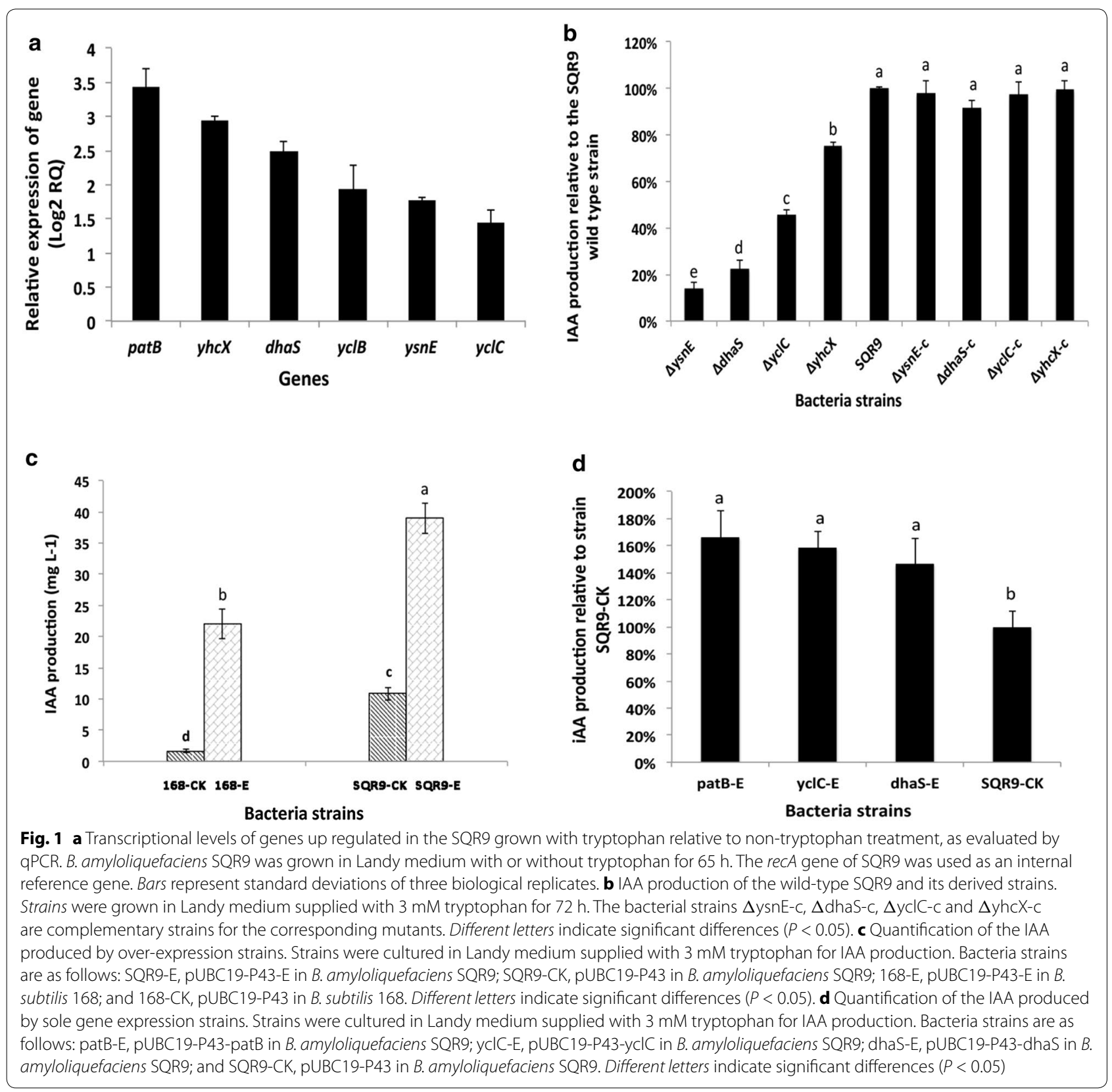

\section{Cloning and expression of the indole-3-pyruvic acid pathway and related genes for IAA biosynthesis}

From the above results, genes constituting a possible entire IPyA pathway were identified in SQR9: patB, predicted to encode an aminotransferase that catalyzes the conversion of tryptophan to indole-3-pyruvate acid, $y c l C$, encoding an UbiD family decarboxylase involved in the conversion of indole-3-pyruvate acid to indole-3-acetaldehyde, and dhaS, encoding indole-3-acetaldehyde dehydrogenase to catalyze the last step of IPyA, converting indole-3-acetaldehyde to IAA. The three genes were separately or tandemly cloned into pUBC19 under the control of the $P 43$ promoter and then homologously expressed in strain SQR9 with the empty vector pUBC19P43 served as control (Fig. 2). The potential IPyA pathway cluster was also heterologously expressed in strain B. subtilis 168 for further verification of its function since B. subtilis 168 showed much lower IAA production compared to that of SQR9 (Fig. 1c). Results showed IAA production of strains patB-E, yclC-E, dhaS-E were increased by $66.7,58.8$ and $47.1 \%$ compared to SQR9-CK, respectively, when cultured in Landy medium supplemented 


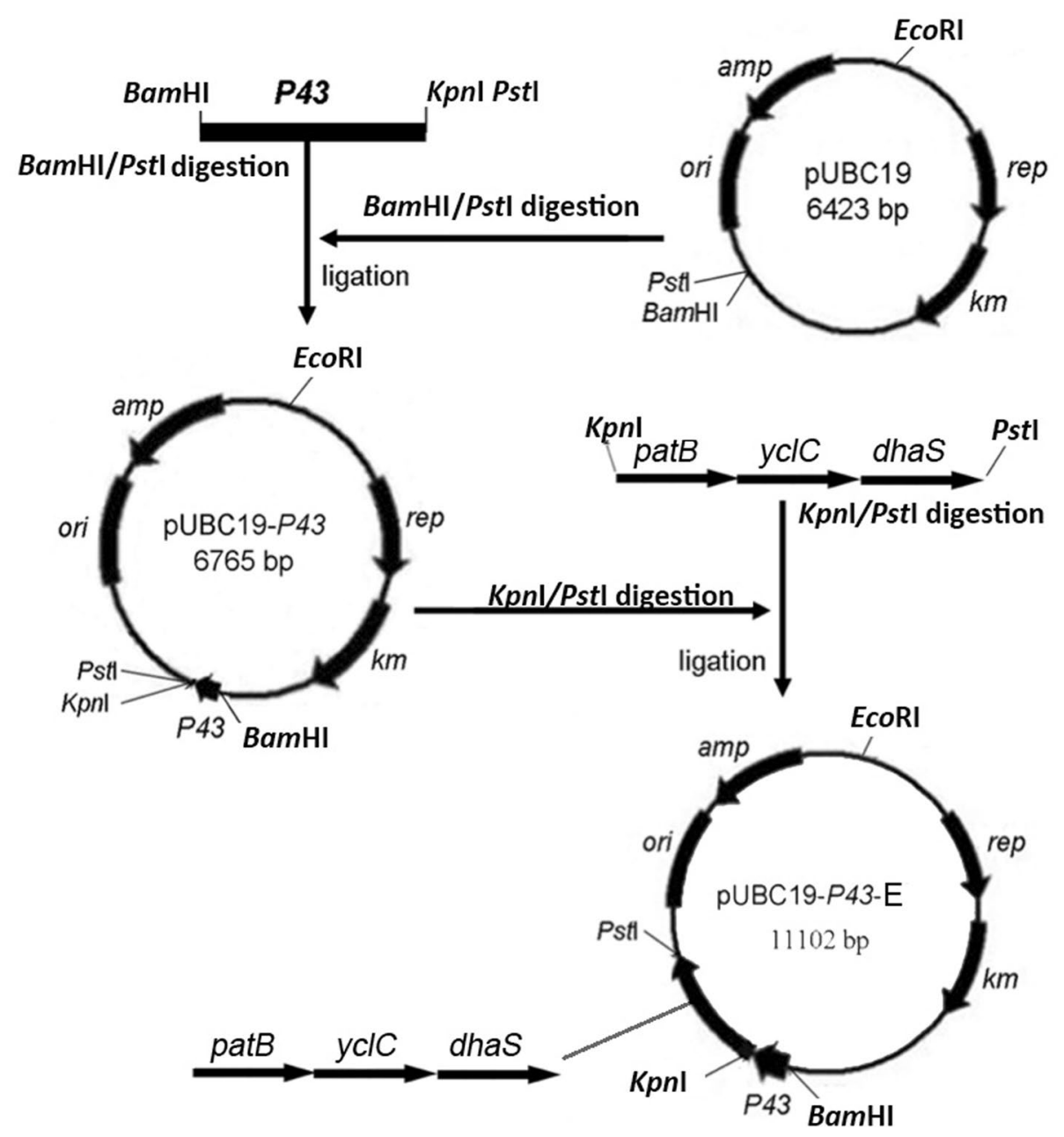

Fig. 2 Construction of plasmids for expression. The P43 promoter from B. subtilis 168 chromosomal DNA was introduced into the shuttle vector pUBC 19 between the BamHI and Pstl sites, and the recombinant plasmid was defined as pUBC19-P43. Genes for expression were PCR-amplified and were spliced by overlap extension. A Kpnl site was introduced into the forward primer of patB, and a Pstl site was introduced into the reverse primer of dhaS. The spliced fragment was ligated to the PUBC19-P43 plasmid in the Kpnl and Pstl sites, and the recombinant plasmid was named pUBC19P43-E

with $3 \mathrm{mM}$ tryptophan (Fig. 1d). Co-expression of the potential entire IPyA pathway cluster in SQR9 (strain SQR9-E) and B. subtilis 168 (strain 168-E) increased nearly 3.6 times $\left(39 \mathrm{mg} \mathrm{L}^{-1}\right)$ and 13.1 times $\left(22 \mathrm{mg} \mathrm{L}^{-1}\right)$ of IAA production compared with the empty vectors controls (SQR9-CK and 168-CK), respectively (Fig. 1c).

\section{Discussion}

B. amyloliquefaciens SQR9 was isolated from cucumber rhizosphere with the capability to protect the host from pathogen invasion and promote the growth of cucumber [44]. Genomic analysis of B. amyloliquefaciens SQR9 revealed that several genes potentially contribute to its plant-growth-promoting effects. An entire set of alsRSD genes implicated in acetoin synthesis was identified.
Moreover, the phy gene, which encodes phytase in Bacillus spp., was also identified in B. amyloliquefaciens SQR9. It was demonstrated that biosynthesis of phytase, acetoin and 2,3-butanediol in B. amyloliquefaciens SQR9 may affect its ability to promote plant growth (Fig. 3) [49]. In this study, we aimed to investigate the phytohormone IAA secreted by SQR9 and to identify possible IAA biosynthesis pathways in SQR9.

Taking advantage of the whole-genome sequence of SQR9, we used genomic scanning and related studies to investigate the key genes in the IAA biosynthesis pathways. The IPyA, TAM, and IAN pathways, as well as an uncharacterized pathway, were believed to participate in IAA biosynthesis of SQR9, according to the analysis of reverse transcription and of gene-knockout mutations. 


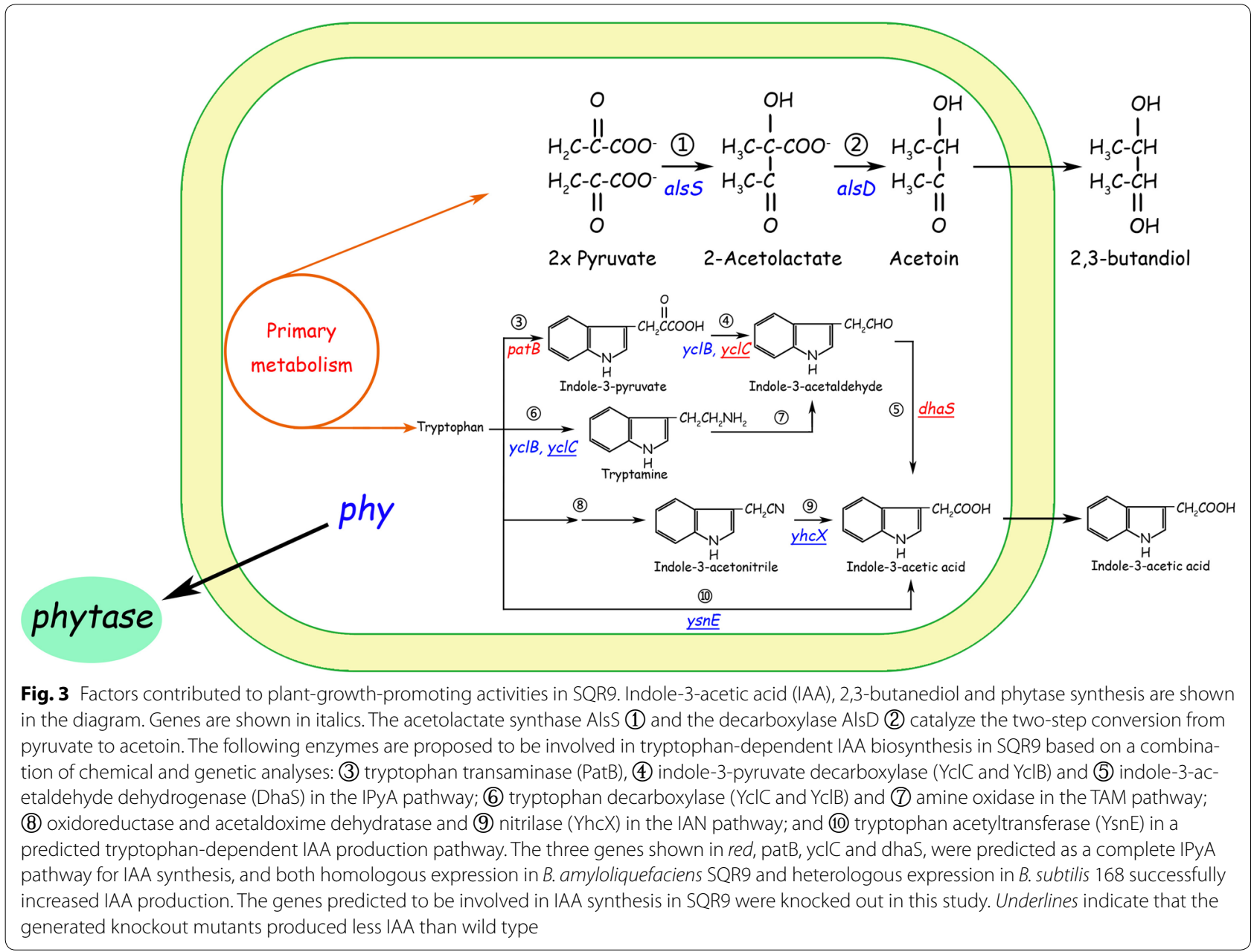

The uncharacterized IAA biosynthesis pathway appeared to be the most important route in SQR9 because IAA production by the $y s n E$ gene knockout mutant was only $14 \%$ of the wild type. The IPyA and TAM pathways also made substantial contributions, but the IAN pathway only contributed minorly IAA production in SQR9.

Genes involved in the IAM pathway, which has been described mainly in phytopathogenic bacteria, were not detected in the SQR9 genome. This two-step pathway has been reported for other PGPR strains. The IAN pathway has been suggested in $A l$. faecalis $[37,38]$ and P. syringae B728a [39] and was believed to contribute to IAA production in B. amyloliquefaciens FZB42 [9]. In B. amyloliquefaciens FZB42, YhcX was predicted to act as a nitrilase based on its similarity to nitrilase 2 of $A$. thaliana, which catalyzes the final step of the IAN pathway [50]. The $y h c X$ gene was also detected in the SQR9 genome, but knockout of this gene only led to a $24 \%$ decrease in IAA production. IAA production in the $y s n E$ gene mutant was only $14 \%$ of the wild type, but this specific metabolic process is poorly studied. The predicted product of the $y s n E$ gene belongs to the $\mathrm{N}$-acetyltransferase superfamily of various enzymes that catalyze the transfer of an acyl group to a nitrogen atom on the acceptor molecule. In B. amyloliquefaciens FZB42, this protein is similar to a putative tryptophan acetyltransferase gene localized within the tryptophan biosynthesis gene cluster in $A z$. brasilense and has been predicted to participate in tryptophan-dependent IAA production [9, 51, 52], while in Bacillus strains, this gene locates away from the tryptophan biosynthesis gene cluster. We deduced that the $y \operatorname{sn} E$ gene product is one of the most important intermediates in $B$. amyloliquefaciens strains, and in-depth study of the role of this gene in IAA biosynthesis will have great significance.

Most beneficial bacteria produce IAA via the IPyA pathway [24]. In our study, gene products of $p a t B, y c l C$ and $d h a S$ were proposed to constitute the entire IPyA pathway in SQR9. Both homologous expression in $B$. amyloliquefaciens SQR9 and heterologous expression in B. subtilis 168 successfully led to increased IAA production with tryptophan supplied in the medium. In Bacillus strains, the patB gene was defined as a putative 
aminotransferase in the aspartate aminotransferase family. This family belongs to the pyridoxal phosphate (PLP)-dependent aspartate aminotransferase (AAT) superfamily, whose members catalyze four types of reactions: transamination (movement of amino groups), racemization (redistribution of enantiomers), decarboxylation (removing $\mathrm{COOH}$ groups), and various side-chain reactions. The major groups in this conserved domain correspond to aspartate aminotransferase a, b, and c and to other amino acids, including aromatic amino acids, such as tryptophan. A previous study constructed two AAT mutants of Rhizobium meliloti and revealed that neither was essential for the biosynthesis of IAA in the absence of exogenous tryptophan but both contributed to IAA biosynthesis when high levels of exogenous tryptophan were present [53]. The $y c l C$ gene, located in the same operon as $y c l B$, was considered a hypothetical protein, possibly encoding a decarboxylase from the UbiD family, which contains several different decarboxylases. The gene product of $y c l C$ was predicted to be an indole-3-pyruvate decarboxylase, which has no significant similarity with the reported indole-3-pyruvate decarboxylase in other organisms. Neither do the $y c l C$ gene has significant similarity with recent reported flavin monooxygenase YUCCA1 that directly converts IPyA to IAA in Arabidopsis [54-56]. The gene responsible for the aldehyde oxidation step of the IPyA pathway in bacteria remains elusive. DhaS, similar to aldehyde dehydrogenase, which likely catalyze the final reaction of the IPyA pathway, has not been considered to be involved in IAA synthesis in B. amyloliquefaciens FZB42 [9, 51]. However, in SQR9, the gene product of dhaS is demonstrated to be involved in IAA synthesis because IAA production of this gene knockout mutant was only $23 \%$ of the wild type. The differences between SQR9 and FZB42 strains, which belong to the same species, might be caused by individual differences, as strain SQR9 could produce much more IAA with tryptophan supplied than strain FZB42 reported by Idris et al. [9]; IAA produced by mutant strains of FZB42 were quantified without tryptophan supplied, although very few, bacteria synthesis tryptophan from indole itself [57], while in our study, IAA production was always quantified with tryptophan supplied [9].

The patB gene was up regulated in reverse-transcription analysis, but its gene deficient mutant strain did not show lower IAA production, and the over expression experiment confirmed that this gene participates in the IPyA pathway. This suggests that although it responds to tryptophan sensitively, the gene product of patB might not be the solely gene responsible for the aminotransferase reaction. The $y h c X$ gene encoding the putative nitrilase was markedly up regulated in the reverse-transcription analysis, whereas $\Delta \mathrm{yhcX}$ only showed a $24 \%$ decrease in IAA production. These confusing phenomena might be explained as follows: (1) it is possible that strain SQR9 possesses several different isoforms of the enzyme for IAA synthesis, each able to utilize multiple substrates, as Kittell et al. [53] reported that aromatic amino acid aminotransferase can act upon all three aromatic amino acids. Furthermore, although ipdC-encoded indolepyruvate decarboxylases from some bacteria have high affinity for indolepyruvate, they can also utilize phenylpyruvate, pyruvate and benzoylformate as substrates [42, 58-60]. (2) As reported for $B$. megaterium, several genes that encode isozymes of glucose dehydrogenase are known [61], and the aminotransferase and nitrilase steps contain multiple enzymes acted as isozymes. When the patB and $y h c X$ genes were inactivated, other genes functioned as isozymes. In bacteria, nitrilases belong to a large family. Branch I Nitrilases are known to have true nitrilase activity $[62,63]$, which may be implicated in IAA biosynthesis. (3) The gene product of pat $B$ acts as an aminotransferase, converting tryptophan to indole-3-pyruvic acid, suggesting that patB gene product is not only a likely immediate precursor for IAA biosynthesis but also a precursor for indolelactic acid (ILA) and tryptophol (Tol), which have been identified as products of physiological origin in Agrobacterium tumefaciens [30]. (4) There are different pathways to synthesize IAA in bacteria, the break down of one pathway could enhance the others. Thus, we concluded that the primary roles of the genes identified in this study might not be the production of IAA; rather, their involvement in the IAA synthesis pathway is incidental. Furthermore, we speculate that each step of the IAA synthesis pathway might contain several isozymes. Therefore, the roles of the reactions catalyzed by the six gene products in IAA biosynthesis in SQR9 remain to be elucidated. Feeding experiments, double and triple mutant analysis, appropriate labeling studies and identification of biosynthetic intermediates will be required to uncover the metabolic route for tryptophan-dependent IAA synthesis in SQR9.

\section{Conclusions}

In conclusion, the results presented here identified six genes involved in IAA biosynthesis of $B$. amyloliquefaciens SQR9 by transcription and IAA quantification analysis of the relevant mutants. The predicted tryptophan-dependent IAA biosynthesis pathways in SQR9 were shown in Fig. 3, and pathways such as IAN, TAM, IPyA and an uncharacterized pathway, which was supposed to be the most important one, are suggested to appear in this strain. Moreover, a possible IPyA pathway for IAA biosynthesis, consisting of patB, yclC and dhaS, was confirmed through homologous and heterologous 
expression in B. amyloliquefaciens SQR9 and B. subtilis 168. This study deepened our understanding of IAA biosynthesis in B. amyloliquefaciens SQR9 and provided molecular evidence for genetic modification of Bacillus spp. for better agricultural application. The overexpression strain of SQR9 produced more IAA and this strain has the potential to be more efficiently to promote plant growth.

\section{Methods}

\section{Strains and growth conditions}

The strains and plasmids used in this study are described in Table 1. B. amyloliquefaciens SQR9 (China General Microbiology Culture Collection Center, CGMCC accession no. 5808) was isolated from the rhizosphere of cucumber. E. coli top10 was used as the host for all plasmids, and B. subtilis 168 was used as the host for heterologous expression of the IAA biosynthesis pathway genes. $B$. amyloliquefaciens SQR9 and B. subtilis 168 were grown at $30{ }^{\circ} \mathrm{C}$ in low-salt Luria-Bertani (LLB) medium (peptone, $10 \mathrm{~g} \mathrm{~L}^{-1}$; yeast extract, $5 \mathrm{~g} \mathrm{~L}^{-1}$; $\mathrm{NaCl}, 5 \mathrm{~g} \mathrm{~L}^{-1}$ ) solidified

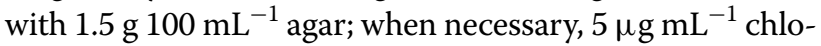
ramphenicol $(\mathrm{Cm})$ or $20 \mu \mathrm{g} \mathrm{mL}{ }^{-1}$ kanamycin $(\mathrm{Km})$ was added. E. coli top10 was grown in LLB medium at $37{ }^{\circ} \mathrm{C}$; when required, $\mathrm{Cm}$ was added to a final concentration of $12.5 \mu \mathrm{g} \mathrm{mL}^{-1}$ or $\mathrm{Km}$ to $30 \mu \mathrm{g} \mathrm{mL}^{-1}$. For IAA production, the bacteria were grown for $72 \mathrm{~h}$ in Landy medium [64] containing $3 \mathrm{mM} \mathrm{L}$-tryptophan at $25^{\circ} \mathrm{C}$ and $90 \mathrm{rpm}$.

\section{Genome analysis of genes involved in IAA production in SQR9}

Based on the whole-genome nucleotide sequence of SQR9 (NCBI accession no. CP006890), the function of all protein-coding genes in SQR9 against reference genomes of B. amyloliquefaciens FZB42 [51] and B. subtilis 168 [65] was obtained by using BLASTP (parameters: $e$-value: $1 \mathrm{e}-5$, coverage $>60 \%$, identity $>50 \%$ ). The genes were identified according to their deduced protein domains, which show putative enzyme activities already known in IAA metabolism.

\section{Reverse transcription analysis of genes involved in IAA synthesis}

RNA was isolated from B. amyloliquefaciens SQR9 cells fermented in Landy medium with or without $3 \mathrm{mM}$ L-tryptophan at $65 \mathrm{~h}$ post-inoculation. The cells were harvested by centrifugation at $4{ }^{\circ} \mathrm{C}(10 \mathrm{~min}$, $5000 \times g)$. Total RNA samples were extracted using an RNAiso Plus kit (TaKaRa, Dalian, China) according to the manufacturer's protocol. RNA was reverse-transcribed into cDNA in a $20-\mu \mathrm{L}$ reverse transcription system (TaKaRa, Dalian, China) according to the manufacturer's instructions.
Transcription levels of genes potentially involved in SQR9 IAA biosynthesis with or without tryptophan in the growth medium were measured by quantitative reverse transcription PCR (qRT-PCR) using a SYBR Premix Ex Taq kit (TaKaRa, Dalian, China). The primers used to amplify these genes are listed in Transcription analysis part of Additional file 2: Table S1. The recA gene of SQR9 was served as an internal control. Reactions were carried out on an ABI 7500 system under the following conditions: cDNA was denatured for $10 \mathrm{~s}$ at $95^{\circ} \mathrm{C}$, followed by 40 cycles of $5 \mathrm{~s}$ at $95^{\circ} \mathrm{C}$ and $34 \mathrm{~s}$ at $60^{\circ} \mathrm{C}$. The $2^{-\Delta \Delta C T}$ method was used to analyze the qRT-PCR data.

\section{Gene knockout by allelic exchange}

To delete the genes of B. amyloliquefaciens SQR9, fragments of approximately $1 \mathrm{~kb}$ in length both upstream and downstream of each target gene were amplified. The 1.1-kb chloramphenicol resistance gene $\left(\mathrm{Cm}^{\mathrm{r}}\right)$ was amplified from plasmid pNW33n with primers, which were partially overlapped with the upstream and downstream fragments of each target gene. Upstream and downstream fragments were fused with the chloramphenicol resistance gene by overlap extension. Primers used in this experiment are shown in Gene knockout part of Additional file 2: Table S1. The $25 \mu \mathrm{l}$ mixture for the first step of the overlapping PCR is as follows: $13.2 \mu \mathrm{L}$ water, $5 \mu \mathrm{L}$ PrimeSTAR buffer $(5 \times), 2 \mu \mathrm{L}$ dNTP mix ( $2.5 \mathrm{mM}$ each), $1.5 \mu \mathrm{L}(15 \mathrm{ng})$ upstream fragment, $1.5 \mu \mathrm{L}$ (15 ng) downstream fragment, $1.5 \mu \mathrm{L}(15 \mathrm{ng}) \mathrm{Cm}^{\mathrm{r}}$ fragment, and 0.3 $\mu \mathrm{L}$ PrimeSTAR HS DNA polymerase. The PCR program was as follows: $98{ }^{\circ} \mathrm{C}$ for $2 \mathrm{~min}, 98^{\circ} \mathrm{C}$ for $10 \mathrm{~s}, 56^{\circ} \mathrm{C}$ for $10 \mathrm{~s}$ and $72{ }^{\circ} \mathrm{C}$ for $3.5 \mathrm{~min}, 15$ cycles. The second step of overlapping PCR, the mixture included $16.7 \mu \mathrm{L}$ water, $5 \mu \mathrm{L}$ PrimeSTAR buffer, $2 \mu \mathrm{L}$ dNTP mix, $1 \mu \mathrm{L}$ forward primer for the upstream fragment, $1 \mu \mathrm{L}$ reverse primer for the downstream fragment, $1 \mu \mathrm{L}$ unpurified product from the first PCR step, and $0.3 \mu \mathrm{L}$ PrimeSTAR HS DNA polymerase. The PCR program was as follows: $98{ }^{\circ} \mathrm{C}$ for $2 \mathrm{~min}, 98{ }^{\circ} \mathrm{C}$ for $10 \mathrm{~s}, 52{ }^{\circ} \mathrm{C}$ for $10 \mathrm{~s}$ and $72{ }^{\circ} \mathrm{C}$ for $3.5 \mathrm{~min}$, 32 cycles. All PCR products were gel-purified using an AxyPrep DNA gel purification and extraction kit (Axygen, Hangchow, USA).

The fused fragments for the target genes were individually transformed into competent cells of B. amyloliquefaciens SQR9 [41], and the transformants were selected on LLB agar plates containing $5 \mu \mathrm{g} \mathrm{mL}^{-1} \mathrm{Cm}$. The correct mutants were verified by PCR using the primer sets in Mutant verification part of Additional file 2: Table S1.

\section{Complementation of the disrupted genes}

Plasmid pUBC19-X (X represents genes of dhaS, yclC, $y h c X$ and $y s n E$ ) were constructed to complement each deleted gene in SQR9 mutants. Primers used in this study 
are shown in Complementary experiment part of Additional file 2: Table S1. The dhaS and $y s n E$ genes (including their promoters), bordered by primer-introduced Pst $\mathrm{I}$ and $B a m H I$ sites, were amplified from SQR9 genomic DNA using the primers dhaScF/dhaScR and ysnEcF/ ysnEcR. The $y c l C$ and $y h c X$ genes (except for their promoters) bordered by primer-introduced PstI and $K p n \mathrm{I}$ sites $(\mathrm{yclCcF} / \mathrm{yclCcR}$ and $\mathrm{yhcXcF} / \mathrm{yhcXcR}$ ) were amplified. After purification and digestion with the corresponding restriction enzymes, the fragments of dhaS and $y s n E$ were cloned into the B. amyloliquefaciens-E. coli shuttle vector $\mathrm{pUBC} 19 ; y c l C$ and $y h c X$ gene fragments were ligated into the pUBC19-P43 vector, which is described in a subsequent section, under the control of the $P 43$ promoter from $B$. subtilis 168 for their promoters remain uncertain. Plasmids were sequenced to confirm their fidelity and then transformed into each corresponding mutant strain of SQR9 to obtain complemented strains.

\section{IAA production analysis}

Wild-type and gene knock-out mutants of SQR9 and $B$. subtilis 168 strains were propagated overnight in $3 \mathrm{~mL}$ Landy medium, and then, $1 \mathrm{ml}$ aliquots were transferred into $100 \mathrm{~mL}$ Landy medium supplied with $3 \mathrm{mM}$ L-tryptophan. After incubation for $72 \mathrm{~h}$, the density of each culture was measured spectrophotometrically at $600 \mathrm{~nm}$, each of the cell culture was adjusted to $\mathrm{OD}_{600}=5.0$ with sterilized water and then the cells of SQR9, B. subtilis 168 and mutant strains were removed by centrifugation $\left(5000 \times g, 20 \mathrm{~min}, 4{ }^{\circ} \mathrm{C}\right)$. Next, $50 \mu \mathrm{L}$ culture supernatant of each strain was subjected to ELISA analysis with the IAA ELISA KIT (Cloud-Clone Crop. USA), and the IAA content was quantified. Liquid cultures $(100 \mathrm{~mL})$ of each strain were adjusted to $\mathrm{pH} 2.5$ with $1.0 \mathrm{M} \mathrm{HCl}$ and extracted three times with ethyl acetate $(1: 3, \mathrm{v} / \mathrm{v})$. The organic solvents were vacuum-dried at $37{ }^{\circ} \mathrm{C}$ and then dissolved in $3 \mathrm{ml}$ methanol. The extract samples were filtered through a $0.45-\mu \mathrm{m}$ membrane before analysis. Extracted samples were separated with Reverse Phase High Performance Liquid Chromatography (RP-HPLC) using a reversed-phase $\mathrm{C} 18$ analytical column (9.4 by $150 \mathrm{~mm}$; Agilent Technologies, Santa Clara, CA). The mobile phase was methanol-0.1 \% acetic acid (60/40) at a flow rate of $0.4 \mathrm{~mL} \mathrm{~min}^{-1}$ for $25 \mathrm{~min}$ at $220 \mathrm{~nm}$ using a UV detector. IAA was quantified by integrating the areas under peaks with the help of authentic IAA from Sigma. The molecular weight of IAA identified by RP-HPLC was determined by an Agilent 6410 triple quadrupole LC/MS apparatus (Agilent Technologies). The electrospray needle was operated at a spray voltage of $4.5 \mathrm{kV}$ and a capillary temperature of $300{ }^{\circ} \mathrm{C}$. The mobile-phase components were methanol-0.1\% acetic acid (60/40) at a flow rate of $0.4 \mathrm{ml} \mathrm{min}^{-1}$. Data acquisition was done in the positive ion mode.

\section{Expression of the identified genes or indole-3-pyruvic acid pathway cluster of SQR9}

Primers P43F/P43R (Additional file 2: Table S1) were used to clone the $P 43$ promoter sequence from $B$. subtilis 168 chromosomal DNA; the BamHI site was introduced into the forward primer P43F, KpnI and PstI sites were introduced into the reverse primer P43R. The P43 fragment was inserted into the shuttle vector pUBC19 between the BamHI and PstI sites, and the recombinant plasmid was designated as pUBC19-P43 (Fig. 2). Genes for expression were PCR-amplified with the primers shown in Additional file 2: Table S1. For single gene expression, a KpnI site was introduced into the forward primer and a PstI site was introduced into the reverse primer of each gene. For gene cluster expression, a КpnI site was introduced into the forward primer of patB, and a PstI site was introduced into the reverse primer of dhaS. The PCR fragments for gene cluster expression were spliced by overlap extension described above. Gene fragments and the pUBC19-P43 plasmid were digested with KpnI and PstI and then ligated together, and the recombinant plasmids were named pUBC19-P43-patB, pUBC19-P43-yclC, pUBC19-P43-dhaS and pUBC19P43-E (Fig. 2).

Plasmids pUBC19-P43-patB, pUBC19-P43-yclC and pUBC19-P43-dhaS were transformed into the competent cells of B. amyloliquefaciens SQR9 [41] to obtain the strains patB-E (pUBC19-P43-patB in SQR9), yclC-E (pUBC19-P43-yclC in SQR9) and dhaS-E (pUBC19-P43dhaS in SQR9). Plasmids pUBC19-P43-E and pUBC19P43 (as empty vector control) were transformed into the competent cells of SQR9 and B. subtilis 168 [66] to obtain the strains SQR9-E (pUBC19-P43-E in SQR9), SQR9CK (pUBC19-P43 in SQR9), 168-E (pUBC19-P43-E in B. subtilis 168), and 168-CK (pUBC19-P43 in B. subtilis 168). Transformants were grown in LLB medium containing $20 \mu \mathrm{g} \mathrm{mL}^{-1} \mathrm{~km}$. For the detection of IAA production, transformants were incubated in Landy medium supplied with tryptophan, and the cultures were analyzed with HPLC and ELISA as described above.

\section{Nucleotide sequence accession numbers}

The GenBank accession numbers for the genes in IAA biosynthesis in the SQR9 genome (NCBI accession no. CP006890) are shown in Table 2. The GenBank accession numbers for the phy gene and the alsRSD gene cluster are V529_21880, V529_35850, V529_35860 and V529_35870, respectively. 


\section{Additional files}

Additional file 1: Figure S1. Relative transcription of genes. Transcriptional levels of genes in the SQR9 grown with tryptophan relative to non-tryptophan treatment evaluated by qPCR. B. amyloliquefaciens SQR9 was grown in Landy medium with or without tryptophan for $65 \mathrm{~h}$. The recA gene of SQR9 was used as an internal reference gene. Bars represent the standard deviations of three biological replicates.

Additional file 2: Table S1. Primers used in this study. Primers used in this study were listed in this table.

\section{Authors' contributions}

JS carried out the molecular genetic studies, participated in genomic analysis, plasmid design, gene knockout and expression, and drafted the manuscript. $S L$ carried out genomic analysis, plasmid design and transcription analysis. NZ participated in the sequence alignment and genomic analysis. XC and XZ participated in IAA production analysis. GZ participated in gene knockout. QS participated in the design of the study and performed the statistical analysis. RZ conceived the study, and participated in its design and coordination, and helped to draft the manuscript. All authors read and approved the final manuscript.

\section{Author details}

${ }^{1}$ Key Laboratory of Microbial Resources Collection and Preservation, Ministry of Agriculture, Institute of Agricultural Resources and Regional Planning, Chinese Academy of Agricultural Sciences, Beijing 100081, People's Republic of China. ${ }^{2}$ Jiangsu Key Lab and Engineering Center for Solid Organic Waste Utilization, Nanjing Agricultural University, Nanjing 210095, People's Republic of China

\section{Acknowledgements}

This research was financially supported by the Chinese Ministry of Science and Technology (2013AA102802), the Fundamental Research Funds for the Central Universities (KYZ201408) and the China Postdoctoral Science Foundation (2014M560430), RZ and QS were also supported by the 111 Project (B12009) and the Priority Academic Program Development (PAPD) of Jiangsu Higher Education Institutions.

\section{Compliance with ethical guidelines}

\section{Competing interests}

The authors declare that they have no competing interest.

Received: 4 June 2015 Accepted: 21 August 2015

Published online: 04 September 2015

\section{References}

1. Bochow H, El-Sayed SF, Junge H, Stavropoulou A, Schmiedeknecht G. Use of Bacillus subtilis as biocontrol agent. IV. Salt-stress tolerance induction by Bacillus subtilis FZB24 seed treatment in tropical vegetable field crops, and its mode of action. Z Für Pflanzenkrankh Pflanzenschutz. 2001;108:21-30.

2. Ryu C-M, Farag MA, Hu C-H, Reddy MS, Wei H-X, Paré PW, Kloepper JW Bacterial volatiles promote growth in Arabidopsis. Proc Natl Acad Sci. 2003;100:4927-32.

3. Yao AV, Bochow H, Karimov S, Boturov U, Sanginboy S, Sharipov AK. Effect of FZB $24{ }^{\circledR}$ Bacillus subtilis as a biofertilizer on cotton yields in field tests. Arch Phytopathol Plant Prot. 2006;39:323-8.

4. Zhang N, Wu K, He X, Li S, Zhang Z, Shen B, Yang X, Zhang R, Huang Q, Shen $\mathrm{Q}$. A new bioorganic fertilizer can effectively control banana wilt by strong colonization with Bacillus subtilis N11. Plant Soil. 2011;344:87-97.

5. Idriss EE, Makarewicz O, Farouk A, Rosner K, Greiner R, Bochow H, Richter T, Borriss R. Extracellular phytase activity of Bacillus amyloliquefaciens
FZB45 contributes to its plant-growth-promoting effect. Microbiology. 2002;148:2097-109.

6. Makarewicz O, Dubrac S, MsadekT, Borriss R. Dual Role of the PhoP $\sim$ P response regulator: Bacillus amyloliquefaciens FZB45 phytase gene transcription is directed by positive and negative interactions with the phyC promoter. J Bacteriol. 2006;188:6953-65.

7. Ping $L$, Boland W. Signals from the underground: bacterial volatiles promote growth in Arabidopsis. Trends Plant Sci. 2004;9:263-6.

8. Ryu C, Farag MA, Hu C, Reddy MS, Kloepper JW, Paré PW. Bacterial volatiles induce systemic resistance in Arabidopsis. Plant Physiol. 2004;134:1017-26.

9. Idris EE, Iglesias DJ, Talon M, Borriss R. Tryptophan-dependent production of indole-3-acetic acid (IAA) affects level of plant growth promotion by Bacillus amyloliquefaciens FZB42. Mol Plant Microbe Interact. 2007;20:619-26.

10. Kochar M, Upadhyay A, Srivastava S. Indole-3-acetic acid biosynthesis in the biocontrol strain Pseudomonas fluorescens Psd and plant growth regulation by hormone overexpression. Res Microbiol. 2011;162:426-35.

11. Kuklinsky-Sobral J, Araújo WL, Mendes R, Geraldi IO, Pizzirani-Kleiner AA, Azevedo JL. Isolation and characterization of soybean-associated bacteria and their potential for plant growth promotion. Environ Microbiol. 2004:6:1244-51.

12. Grossmann K. Auxin herbicides: current status of mechanism and mode of action. Pest Manag Sci. 2010;66:113-20.

13. Phillips KA, Skirpan AL, Liu X, Christensen A, Slewinski TL, Hudson C, Barazesh S, Cohen JD, Malcomber S, McSteen P. vanishing tassel2 encodes a grass-specific tryptophan aminotransferase required for vegetative and reproductive development in maize. Plant Cell Online. 2011;23:550-66.

14. Teale WD, Paponov IA, Palme K. Auxin in action: signalling, transport and the control of plant growth and development. Nat Rev Mol Cell Biol. 2006;7:847-59.

15. Woodward AW, Bartel B. Auxin: regulation, action, and interaction. Ann Bot. 2005;95:707-35.

16. Beyeler M, Keel C, Michaux P, Haas D. Enhanced production of indole3-acetic acid by a genetically modified strain of Pseudomonas fluorescens $\mathrm{CHAO}$ affects root growth of cucumber, but does not improve protection of the plant against Pythium root rot. FEMS Microbiol Ecol. 1999;28:225-33.

17. Hall JA, Peirson D, Ghosh S, Glick BR. Root elongation in various agronomic crops by the plant growth promoting rhizobacterium Pseudomonas putida Gr12-2. Isr J Plant Sci. 1996;44:37-42.

18. Patten CL, Glick BR. Role of pseudomonas putida indoleacetic acid in development of the host plant root system. Appl Environ Microbiol. 2002:68:3795-801.

19. Dobbelaere S, Croonenborghs A, Thys A, Broek AV, Vanderleyden J. Phytostimulatory effect of Azospirillum brasilense wild type and mutant strains altered in IAA production on wheat. Plant Soil. 1999;212:153-62.

20. Ahmed A, Hasnain S. Auxin-producing Bacillus sp.: auxin quantification and effect on the growth of Solanum tuberosum. Pure Appl Chem. 2010:82:313-9.

21. Khalid A, Tahir S, Arshad M, Zahir ZA. Relative efficiency of rhizobacteria for auxin biosynthesis in rhizosphere and non-rhizosphere soils. Soil Res. 2004:42:921-6.

22. Patten CL, Glick BR. Bacterial biosynthesis of indole-3-acetic acid. Can J Microbiol. 1996:42:207-20.

23. Duca D, Lorv J, Patten CL, Rose D, Glick BR. Indole-3-acetic acid in plantmicrobe interactions. Antonie Van Leeuwenhoek. 2014;106:85-125.

24. Spaepen S, Vanderleyden J, Remans R. Indole-3-acetic acid in microbial and microorganism-plant signaling. FEMS Microbiol Rev. 2007;31:425-48.

25. Baudoin E, Lerner A, Mirza MS, El Zemrany H, Prigent-Combaret C, Jurkevich E, Spaepen S, Vanderleyden J, Nazaret S, Okon Y, MoënneLoccoz Y. Effects of Azospirillum brasilense with genetically modified auxin biosynthesis gene ipdC upon the diversity of the indigenous microbiota of the wheat rhizosphere. Res Microbiol. 2010;161:219-26.

26. Costacurta A, Keijers V, Vanderleyden J. Molecular cloning and sequence analysis of an Azospirilium brasilense indole-3-pyruvate decarboxylase gene. Mol Gen Genet MGG. 1994;243:463-72

27. Koga J, Adachi T, Hidaka H. Molecular cloning of the gene for indolepyruvate decarboxylase from Enterobacter cloacae. MGG Mol Gen Genet. 1991;226-226:10-6 
28. Prinsen E, Costacurta A, Michiels K, Vanderleyden J, Vandeputte O. Azospirillum brasilense indole-3-acetic acid biosynthesis: evidence for a non-tryptophan dependent pathway. Mol Plant-Microbe Interact. 1993;6:609-15.

29. Kulkarni GB, Sanjeevkumar S, Kirankumar B, Santoshkumar M, Karegoudar TB. Indole-3-acetic acid biosynthesis in Fusarium delphinoides strain GPK, a causal agent of Wilt in Chickpea. Appl Biochem Biotechnol. 2013;169:1292-305

30. Kaper JM, Veldstra H. On the metabolism of tryptophan by Agrobacterium tumefaciens. Biochim Biophys Acta. 1958;30:401-20.

31. Morris RO. Genes specifying auxin and cytokinin biosynthesis in prokaryotes. In: Davies PJ, editor. Plant hormones and their role in plant growth and development. Springer: Netherlands; 1987. p. 636-55.

32. Sekine M, Watanabe K, Syono K. Molecular cloning of a gene for indole3-acetamide hydrolase from Bradyrhizobium japonicum. J Bacteriol. 1989;171:1718-24.

33. Theunis M, Kobayashi H, Broughton WJ, Prinsen E. Flavonoids, NodD1, NodD2, and Nod-Box NB15 modulate expression of the $y 4$ WEFG locus that is required for indole-3-acetic acid synthesis in Rhizobium sp. strain NGR234. Mol Plant Microbe Interact. 2004;17:1153-61.

34. Perley JE, Stowe BB. On the ability of Taphrina deformans to produce indoleacetic acid from tryptophan by way of tryptamine. Plant Physiol. 1966;41:234-7.

35. Hartmann A, Singh M, Klingmüller W. Isolation and characterization of Azospirillum mutants excreting high amounts of indoleacetic acid. Can J Microbiol. 1983;29:916-23.

36. Bartling D, Seedorf M, Mithöfer A, Weiler EW. Cloning and expression of an Arabidopsis nitrilase which can convert indole-3-acetonitrile to the plant hormone, indole-3-acetic acid. Eur J Biochem. 1992;205:417-24.

37. Kobayashi M, Izui H, Nagasawa T, Yamada H. Nitrilase in biosynthesis of the plant hormone indole-3-acetic acid from indole-3-acetonitrile: cloning of the Alcaligenes gene and site-directed mutagenesis of cysteine residues. Proc Natl Acad Sci. 1993;90:247-51.

38. Nagasawa T, Mauger J, Yamada H. A novel nitrilase, arylacetonitrilase, of Alcaligenes faecalis JM3. Eur J Biochem. 1990;194:765-72.

39. Howden AJM, Rico A, Mentlak T, Miguet L, Preston GM. Pseudomonas syringae $p v$. syringae B728a hydrolyses indole-3-acetonitrile to the plant hormone indole-3-acetic acid. Mol. Plant Pathol. 2009;10:857-65.

40. Normanly J, Cohen JD, Fink GR. Arabidopsis thaliana auxotrophs reveal a tryptophan-independent biosynthetic pathway for indole-3-acetic acid. Proc Natl Acad Sci USA. 1993;90:10355-9.

41. Last RL, Bissinger PH, Mahoney DJ, Radwanski ER, Fink GR. Tryptophan mutants in Arabidopsis: the consequences of duplicated tryptophan synthase beta genes. Plant Cell. 1991;3:345-58.

42. Phi QT, Park YM, Ryu CM, Park SH, Ghim SY. Functional identification and expression of indole-3-pyruvate decarboxylase from Paenibacillus polymyxa E681. J Microbiol Biotechnol. 2008;18:1235-44.

43. Vandeputte O, Öden S, Mol A, Vereecke D, Goethals K, Jaziri ME, Prinsen E. Biosynthesis of auxin by the gram-positive phytopathogen Rhodococcus fascians is controlled by compounds specific to infected plant tissues. Appl Environ Microbiol. 2005;71:1169-77.

44. Cao Y, Zhang Z, Ling N, Yuan Y, Zheng X, Shen B, Shen Q. Bacillus subtilis SQR 9 can control Fusarium wilt in cucumber by colonizing plant roots. Biol Fertil Soils. 2011;47:495-506.

45. Qiu M, Zhang R, Xue C, Zhang S, Li S, Zhang N, Shen Q. Application of bio-organic fertilizer can control Fusarium wilt of cucumber plants by regulating microbial community of rhizosphere soil. Biol Fertil Soils. 2012;48:807-16

46. Xu Z, Zhang R, Wang D, Qiu M, Feng H, Zhang N, Shen Q. Enhanced control of cucumber wilt disease by Bacillus amyloliquefaciens SQR9 by altering the regulation of its DegU phosphorylation. Appl Environ Microbiol. 2014;80:2941-50.

47. Weng J, Wang Y, Li J, Shen Q, Zhang R. Enhanced root colonization and biocontrol activity of Bacillus amyloliquefaciens SQR9 by abrB gene disruption. Appl Microbiol Biotechnol. 2013;97:8823-30.

48. Xu Z, Shao J, Li B, Yan X, Shen Q, Zhang R. Contribution of bacillomycin $\mathrm{D}$ in Bacillus amyloliquefaciens SQR9 to antifungal activity and biofilm formation. Appl Environ Microbiol. 2013;79:808-15.

49. Shao J, Xu Z, Zhang N, Shen Q, Zhang R. Contribution of indole-3-acetic acid in the plant growth promotion by the rhizospheric strain Bacillus amyloliquefaciens SQR9. Biol Fertil Soils. 2014;51:321-30.
50. Hillebrand $H$, Bartling D, Weiler EW. Structural analysis of the nit2/nit1/nit3 gene cluster encoding nitrilases, enzymes catalyzing the terminal activation step in indole-acetic acid biosynthesis in Arabidopsis thaliana. Plant Mol Biol. 1998;36:89-99.

51. Chen XH, Koumoutsi A, Scholz R, Eisenreich A, Schneider K, Heinemeyer I, Morgenstern B, Voss B, Hess WR, Reva O, Junge H, Voigt B, Jungblut PR, Vater J, Süssmuth R, Liesegang H, Strittmatter A, Gottschalk G, Borriss R. Comparative analysis of the complete genome sequence of the plant growth-promoting bacterium Bacillus amyloliquefaciens FZB42. Nat Biotechnol. 2007;25:1007-14.

52. Zimmer W, Aparicio C, Elmerich C. Relationship between tryptophan biosynthesis and indole-3-acetic acid production in Azospirillum: identification and sequencing of a trpGDC cluster. Mol Gen Genet MGG. 1991;229:41-51.

53. Kittell BL, Helinski DR, Ditta GS. Aromatic aminotransferase activity and indoleacetic acid production in Rhizobium meliloti. J Bacteriol. 1989;171:5458-66.

54. Stepanova AN, Yun J, Robles LM, Novak O, He W, Guo H, Ljung K, Alonso JM. The Arabidopsis YUCCA1 flavin monooxygenase function in the indole-3-pyruvic acid branch of auxin biosynthesis. Plant Cell. 2011;23:3961-73.

55. Suzuki M, Yamazaki C, Mitsui M, Kakei Y, Mitani Y, Nakamura A, Ishii T, Soeno K, Shimada Y. Transcriptional feedback regulation of YUCCA genes in response to auxin levels in Arabidopsis. Plant Cell Rep. 2015;34:1343-52

56. Brumos J, Alonso JM, Stepanova AN. Genetic aspects of auxin biosynthesis and its regulation. Physiol Plant. 2014;151:3-12.

57. Arora PK, Sharma A, Bae H. Microbial degradation of indole and its derivatives. J Chem. 2015. doi:10.1155/2015/129159.

58. Patten CL, Blakney AJC, Coulson TJD. Activity, distribution and function of indole-3-acetic acid biosynthetic pathways in bacteria. Crit Rev Microbiol. 2012;39:395-415

59. Schütz A, Golbik R, Tittmann K, Svergun DI, Koch MHJ, Hübner G, König S. Studies on structure-function relationships of indolepyruvate decarboxylase from Enterobacter cloacae, a key enzyme of the indole acetic acid pathway. Eur J Biochem. 2003;270:2322-31.

60. Schütz A, Sandalova T, Ricagno S, Hübner G, König S, Schneider G. Crystal structure of thiamindiphosphate-dependent indolepyruvate decarboxylase from Enterobacter cloacae, an enzyme involved in the biosynthesis of the plant hormone indole-3-acetic acid. Eur J Biochem. 2003;270:2312-21.

61. Nagao T, Mitamura T, Wang XH, Negoro S, Yomo T, Urabe I, Okada H. Cloning, nucleotide sequences, and enzymatic properties of glucose dehydrogenase isozymes from Bacillus megaterium IAM1030. J Bacteriol. 1992;174:5013-20.

62. Pace $H$, Brenner $\mathrm{C}$. The nitrilase superfamily: classification, structure and function. Genome Biol. 2001;2:1-15.

63. Podar M, Eads JR, Richardson TH. Evolution of a microbial nitrilase gene family: a comparative and environmental genomics study. BMC Evol Biol. 2005;5:42.

64. Landy M, Warren GH, RosenmanM SB, Colio LG. Bacillomycin an antibiotic from Bacillus subtilis active against pathogenic fungi. Exp Biol Med. 1948;67:539-41.

65. Kunst F, Ogasawara N, Moszer I, Albertini AM, Alloni G, Azevedo V, Bertero $M G$, Bessières $P$, Bolotin $A$, Borchert $S$, Borriss $R$, Boursier $L$, Brans $A$, Braun M, Brignell SC, Bron S, Brouillet S, Bruschi CV, Caldwell B, Capuano V, Carter NM, Choi S-K, Codani J-J, Connerton IF, Cummings NJ, Daniel RA, Denizot F, Devine KM, Düsterhöft A, Ehrlich SD, Emmerson PT, Entian KD, Errington J, Fabret C, Ferrari E, Foulger D, Fritz C, Fujita M, Fujita Y, Fuma S, Galizzi A, Galleron N, Ghim S-Y, Glaser P, Goffeau A, Golightly EJ, Grandi G, Guiseppi G, Guy BJ, Haga K, Haiech J, Harwood CR, Hénaut A, Hilbert H, Holsappel S, Hosono S, Hullo M-F, Itaya M, Jones L, Joris B, Karamata D, Kasahara Y, Klaerr-Blanchard M, Klein C, Kobayashi Y, Koetter P, Koningstein G, Krogh S, Kumano M, Kurita K, Lapidus A, Lardinois S, Lauber J, Lazarevic V, Lee S-M, Levine A, Liu H, Masuda S, Mauël C, Médigue C, Medina N, Mellado RP, Mizuno M, Moestl D, Nakai S, Noback M, Noone D, O'Reilly M, Ogawa K, Ogiwara A, Oudega B, Park S-H, Parro V, Pohl TM, Portetelle D, Porwollik S, Prescott AM, Presecan E, Pujic P, Purnelle B, Rapoport G, Rey M, Reynolds S, Rieger M, Rivolta C, Rocha E, Roche B, Rose M, Sadaie Y, Sato T, Scanlan E, Schleich S, Schroeter R, Scoffone F, Sekiguchi J, Sekowska A, Seror SJ, Serror P, Shin B-S, Soldo B, Sorokin A, 
Tacconi E, Takagi T, Takahashi H, Takemaru K, Takeuchi M, Tamakoshi A, Tanaka T, Terpstra P, Tognoni A, Tosato V, Uchiyama S, Vandenbol M, Vannier F, Vassarotti A, Viari A, Wambutt R, Wedler E, Wedler H, Weitzenegger T, Winters P, Wipat A, Yamamoto H, Yamane K, Yasumoto K, Yata K, Yoshida K, Yoshikawa H-F, Zumstein E, Yoshikawa H, Danchin A. The complete genome sequence of the Gram-positive bacterium Bacillus subtilis. Nature. 1997;390:249-56.

66. Anagnostopoulos C, Spizizen J. Requirements for transformation in Bacillus subtilis 168. J Bacteriol. 1961:81:741-6.

Submit your next manuscript to BioMed Central and take full advantage of:

- Convenient online submission

- Thorough peer review

- No space constraints or color figure charges

- Immediate publication on acceptance

- Inclusion in PubMed, CAS, Scopus and Google Scholar

- Research which is freely available for redistribution

Submit your manuscript at

www.biomedcentral.com/submit

( ) Biomed Central 